\title{
GREEN NANO ARCHITECTURE: A NEW PROSPECTS AND FUTURE VISIONS
}

\author{
Alaa-aldien Alsaied Farid" ${ }^{1}$ Ahmed Hamed El-Sayed salama ${ }^{2}$ \\ and Rania Said Sayd Mourad ${ }^{3}$ \\ ${ }^{1}$ Department of Architecture, Faculty of Engineering, Al-Azhar University \\ ${ }^{2}$ Department of Civil Engineering, Faculty of Engineering, Al-Azhar University \\ ${ }^{3}$ Development, Research and Studies Department Fund, Ministry of Housing
}

\begin{abstract}
The research study the concept of Nano technology and how integrate it with green practices which begins with the application of the principles green chemistry during the design and manufacture of Nano material to have got green Nano material which it has ability achieve architectural sustainability Adapts to the technological data of this era, and the integration of green Nano material with architecture has led us to green Nano architecture which inspire of solutions and innovative ideas to support architectural sustainability form design to structure. The research also studies many of the factors that represent application of Green nanotechnology (such as construction materials and management its resources for sustainability - energy and sustainability and the use of green and renewable energy - the efficiency of water consumption and Waste Management Waste Management). And how green Nano architecture be a participant in solution a number of environmental issues such as energy consumption, emissions of carbon dioxide, And Recycling of Nano-waste in a sustainable manner.
\end{abstract}

Key Words ; Green Nano Technology - Green Chemical - Sustainable Chemical - Green Nano Architecture -Green Nano Concert - Nano Granite Waste.








شكل (1) طريقة الوصول الى حجم النانو المرجع : (10)


و إعادة تدوير نفايات النانو بطريقة مستدامة النان .






خرسانة النانو الخضر ائ ـ نفايات النانو جرانيت. مقدمة البحث





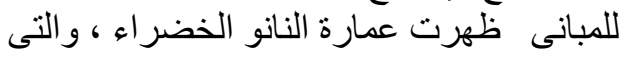


مر احل دورة حياتها حتى تكون تطبيقاً عملياً الإنداً لإندماج تكنولوجيا النانو ومبادى الإه الإستدامة

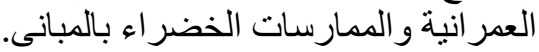



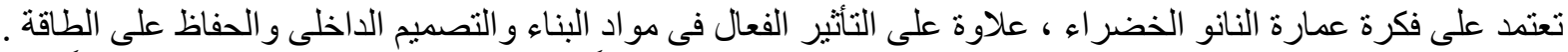







تكمن المشكلة البحثية في كيفية الوصول إلى إستدامة معمارية عن طريق إندماج تكنولوجيا النانو الخضر اءوباء بالعمارة للوصول إلى عمارة النانو الخضر اء من شأنها الإرتقاء بالعمارة و العمل على إستدامتها بما يتو ائم و المعطيات التهات التكنولوجية



القرضية العلمية

مبادىء الكيمياء الخضر اء و إندامجها بطرق تحضير وتضيع مو اد النانو هى الداعم الأساسى للوصول إلى إلى عمارة نانو



هدف البحث بـث

يهدف البحث بشكل رئيسى الى دراسة الأفكار التطبيقية لعمارة النانو الخضر اءو وآلية تطبيقها للوصول إلى عمارة تكنولوجية مستدامة.

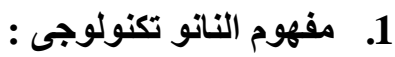





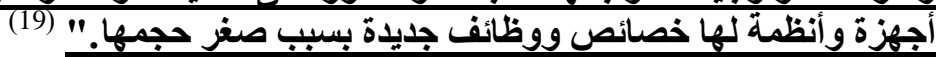










وتوجد طريقتين لتصنيع مواد النانو لانوانو























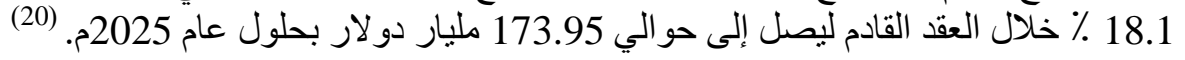


ويوضح شكل (2) حجم مبيعات منتجات النانو تكنولوجى الحالية و المستقبلية ما بين (2015م - 2024 م).

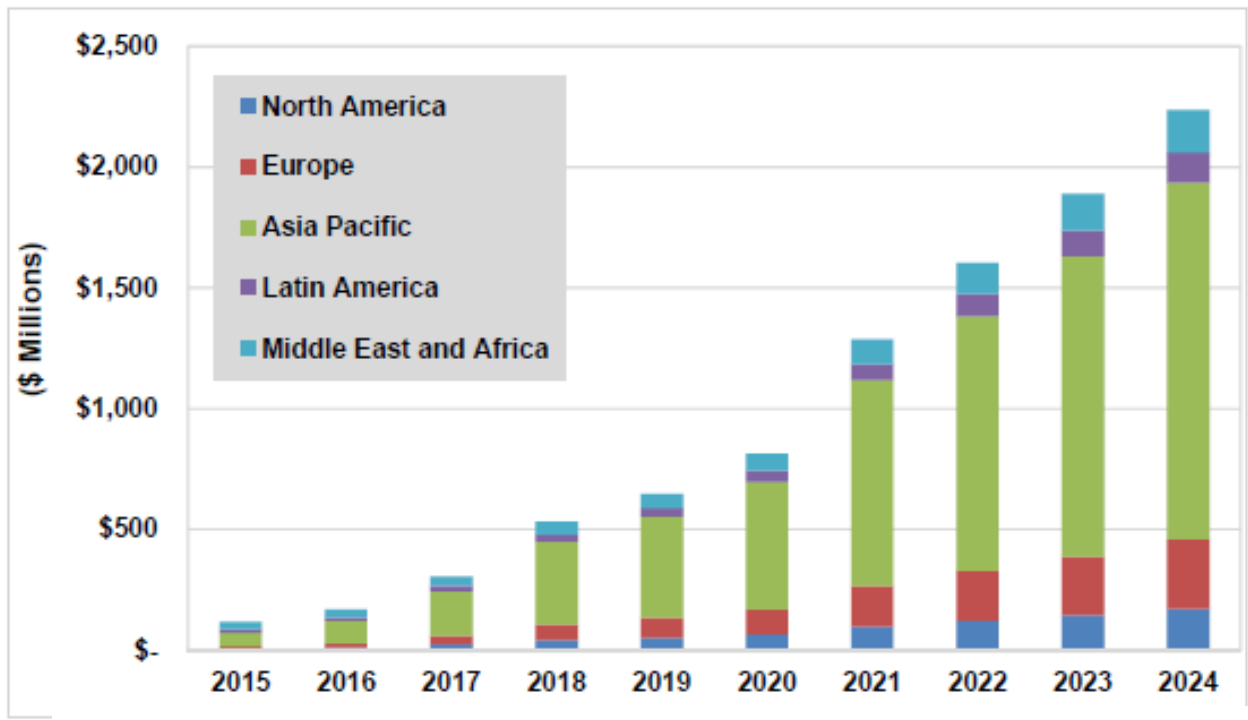

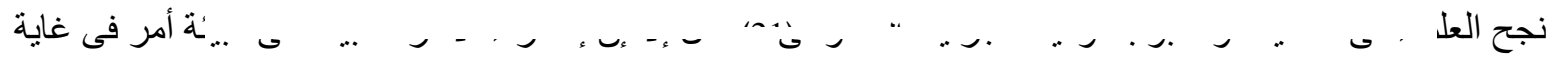

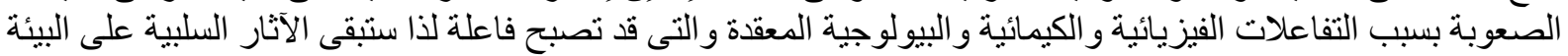

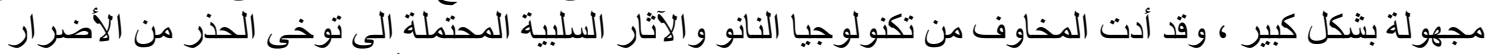

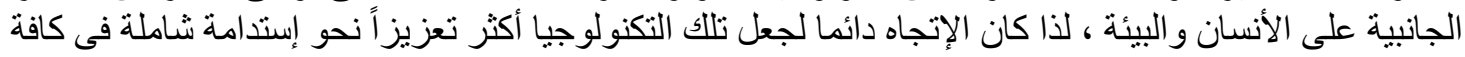

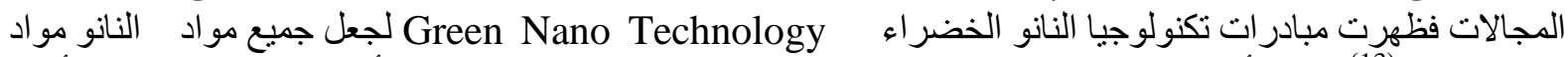


ضرر على الإنسان او البيئة أوحتى موازين القوى البشرية أو الطئية الطبيعية من أجل بيئة منوازنة مستدامة.

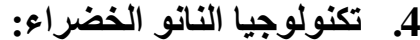

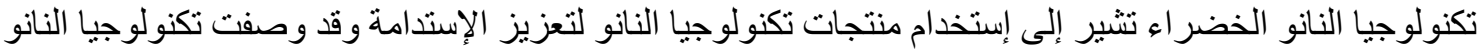

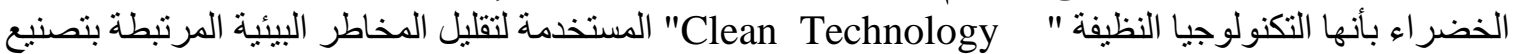

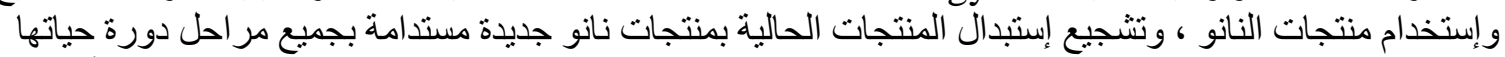

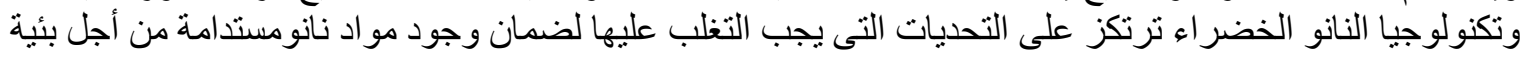
منوازنة.






5. لتكنولوجيا النانو الخضراء هداء هانين:










القدرة على تتظيف مو اقع النفايات الخطرة أو تحلية المياه أومعالجة الملوثات أوكثف الملوثات الثات البيئية ورصدها:
















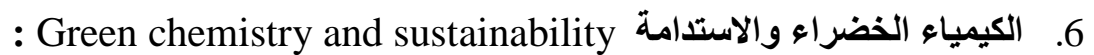

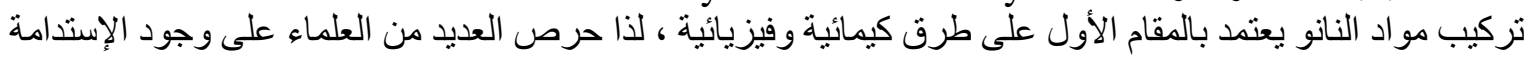

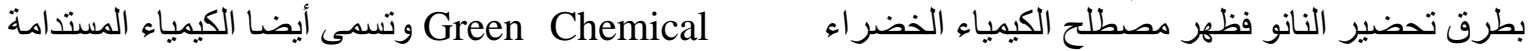

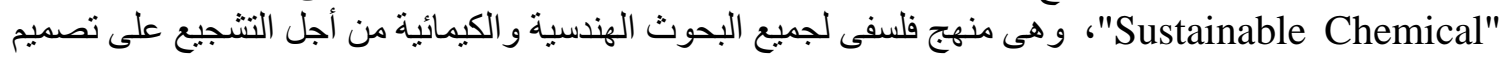

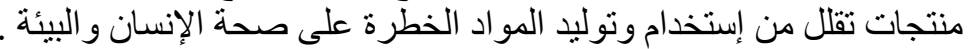

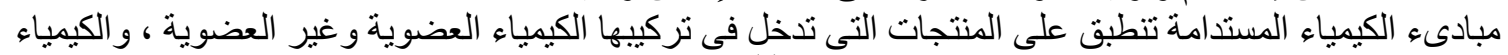
الحيوية ، والكيمياء التحليلية ، وحتى الكئي الكيمياء الفيزيائية.

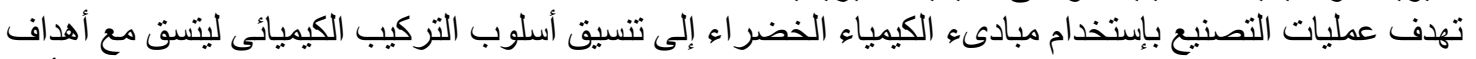

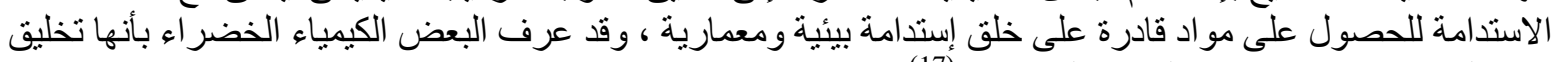

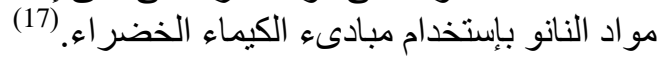

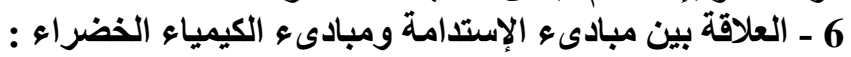

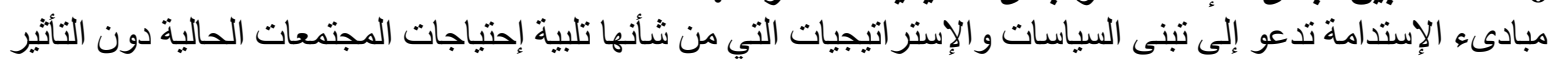



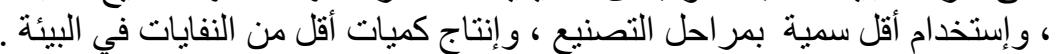



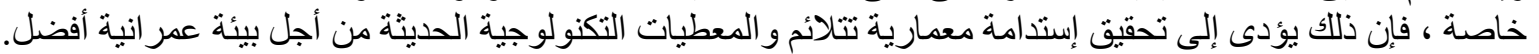

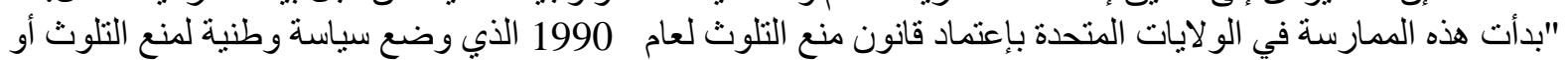






وقوعها". (11) مبادى )






من خلالها تحقيق إستدامة تتو افق وطموح الباحثين و المعمارين بالعصر العراه الحالى ومعطياته التكنولوجية. 7.

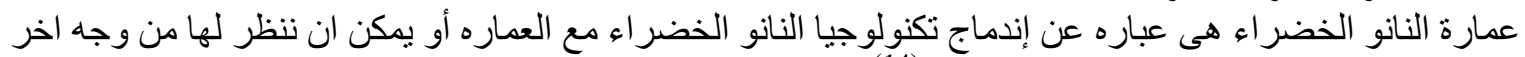

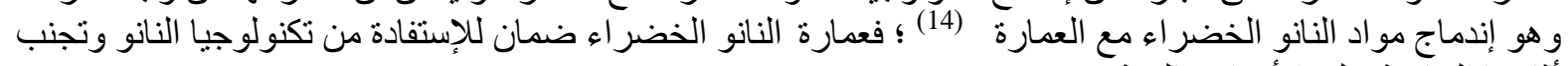
أثار ها الجانبية على الأنسان و البيئة.

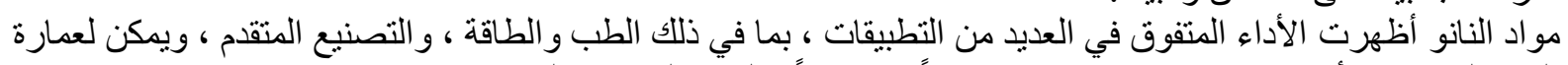

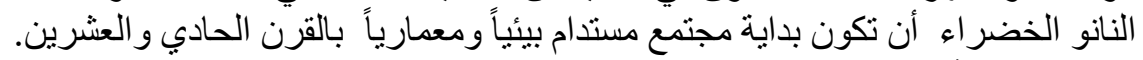

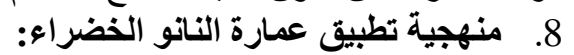

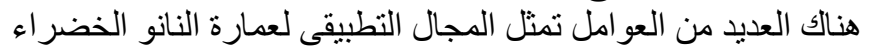

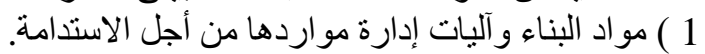

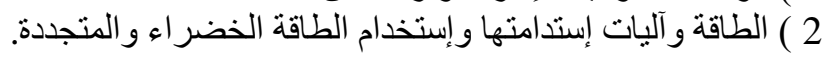
3 ) كفاءة إستهلاك المياه.

4 ) إدارة النفايات Waste Management

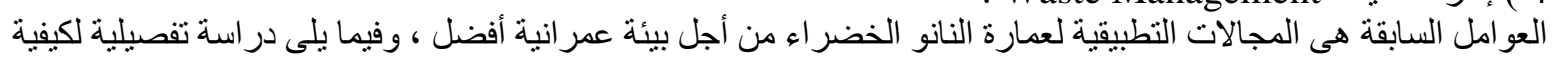

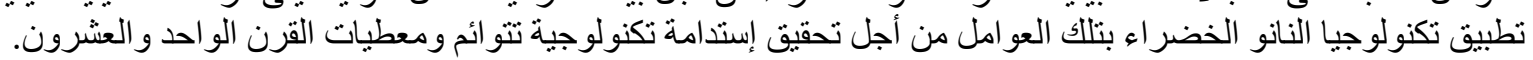


عمارة النانو الخضراء : آفاق جديدة ورؤى مستقبلية

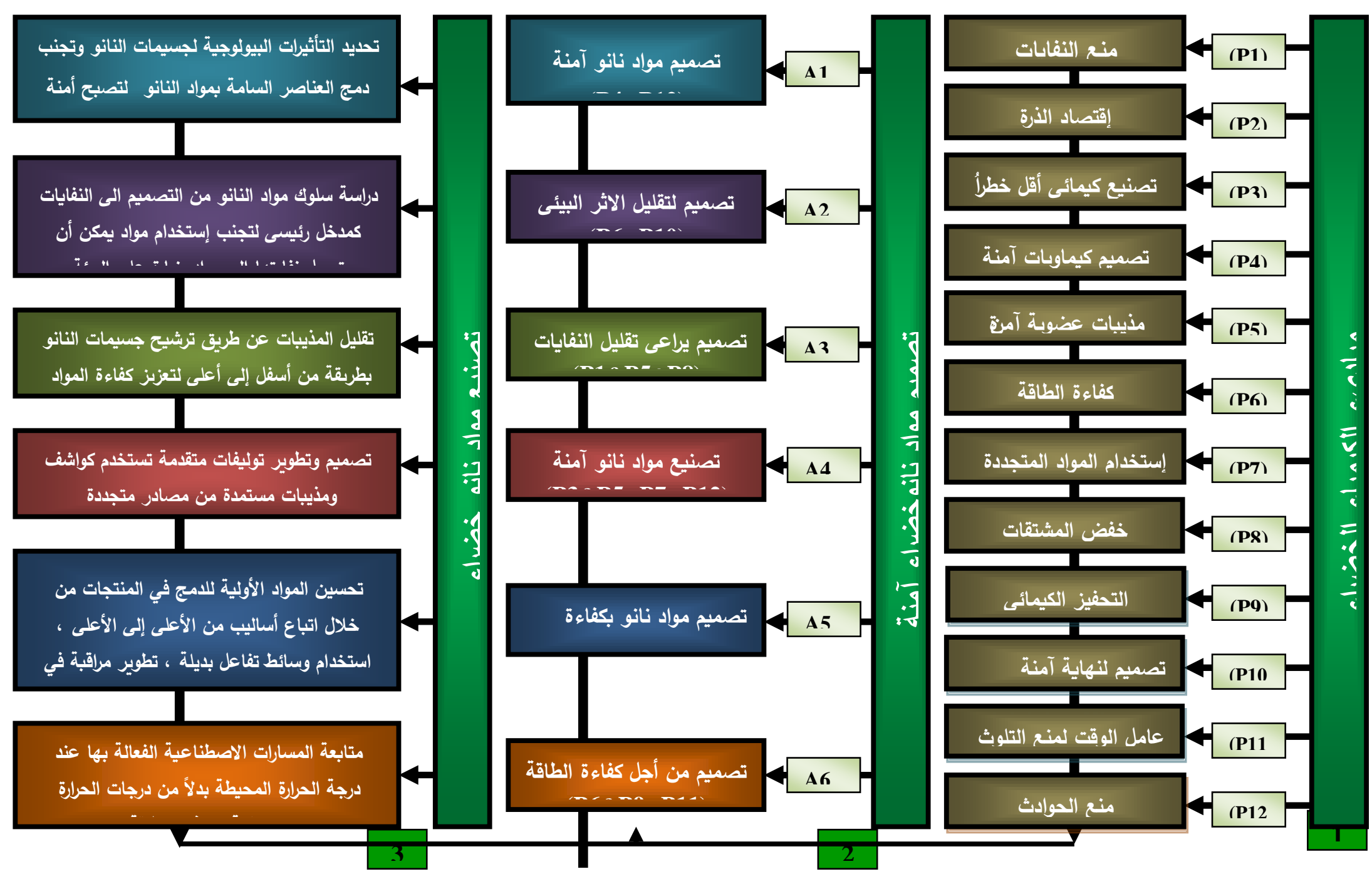

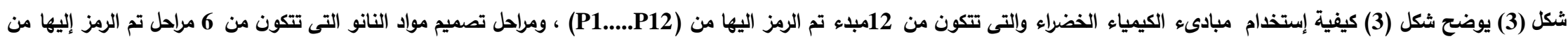

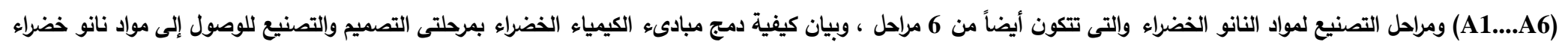


1-8 مواد البناء وآليات إدارة مواردها من أجل الاستدامة:



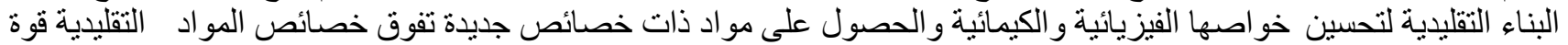

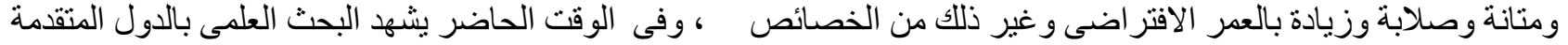

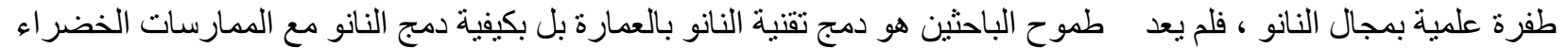

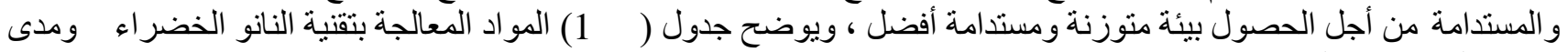
تحقيقها للإستدامة بالمبنى .

\begin{tabular}{|c|c|c|}
\hline نتائج إندماج النانو بالمبانى & تطيقات مواد الناتو بالمبانى & مواد النانو \\
\hline زيادة المتانة و الصدلابة. & 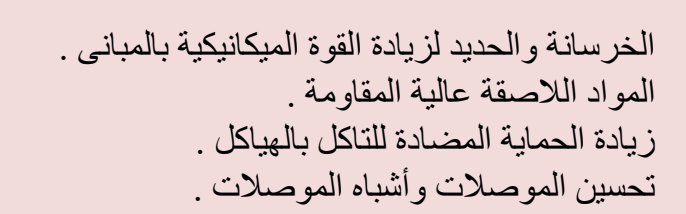 & $\begin{array}{l}\text { أنابيب الكريون } \\
\text { Carbon } \\
\text { nanotubes }\end{array}$ \\
\hline زيادة المتانة و الصلابة. & الخعزيا الضوئية بالاشىتر العناصر مع الميكانيكية . & $\begin{array}{c}\text { الألورين } \\
\text { Fullerene }\end{array}$ \\
\hline الكفاءة فى إستخدام الطاقة. & 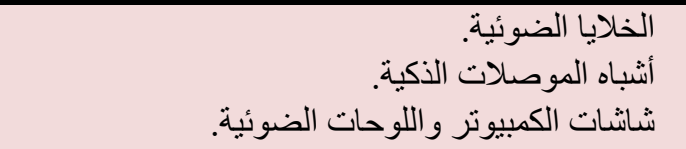 & | \\
\hline الكفاءة فى إستخدام الطاقة. & 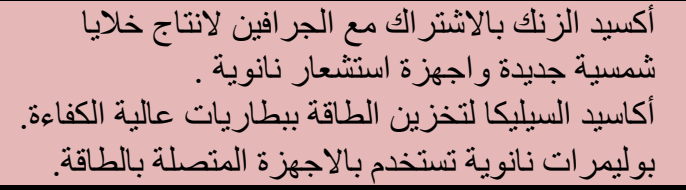 & 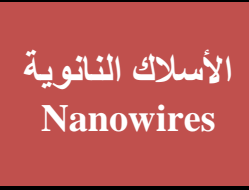 \\
\hline الكفاءة فى إستخدام الطاقة. & البطاريات و الاجهزة المتصلة بالطاقة. & $\begin{array}{l}\text { مواد الكريون } \\
\text { Carbon } \\
\text { nanomaterials }\end{array}$ \\
\hline زيادة المتانة. & 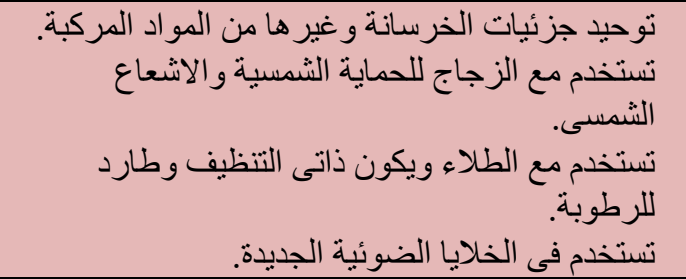 & \begin{tabular}{|c} 
نانو سيليكا \\
Nano--silica
\end{tabular} \\
\hline زيادة المتانة و الصلابة. & التداية حداية حديد التسليح من التاكل وغير ذلك من عو امل & 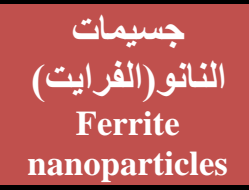 \\
\hline الكفاءة فى استخدام المياه. & معالجة مياه الصرف. & $\begin{array}{c}\text { Nano---metric } \\
\text { cavitation }\end{array}$ \\
\hline كفاءة .جودة المياه. & تستخدم بمرشحات المياه. & $\begin{array}{l}\text { الالومنيون- } \\
\text { Nano- } \\
\text {-alumina }\end{array}$ \\
\hline
\end{tabular}

\section{جدول(1) المواد المعالجة بتقنية النانو الخضراء ومدى تحقيقها لللاستدامة بالمبنى}

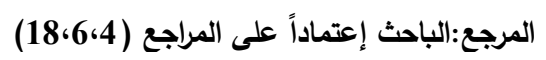




\begin{tabular}{|c|c|c|}
\hline تئتج إندماج النانو بالمبانى & تطبيقات مواد النانو بالإنبّى & 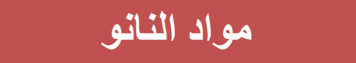 \\
\hline  & 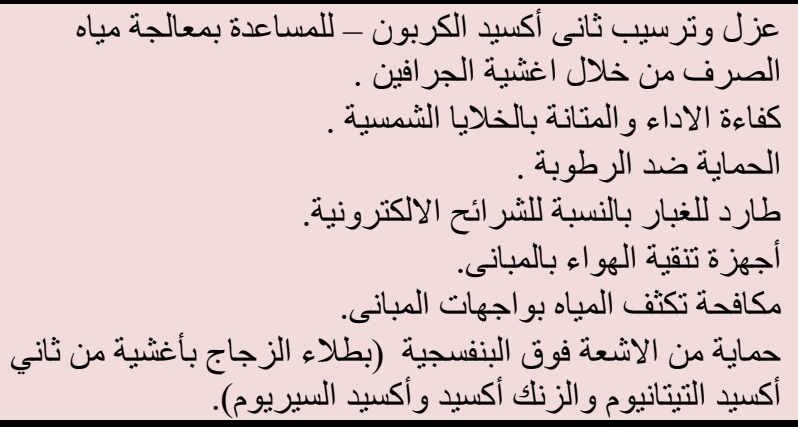 & $\begin{array}{c}\text { أغشية ذُات تركيب ناتو مثر } \\
\text { Nanostructured } \\
\text { membranes }\end{array}$ \\
\hline • الكفاءة فئى إستخدام الطاقة. & مازل مافحة الكتابة على الضية. الجدران. & $\begin{array}{c}\text { Nanostructured thin } \\
\text { fllms }\end{array}$ \\
\hline المحافظة على البيئة الطبيعية & لمعالجة التربة و المياه الملوثة من النفط والمنتجات الثانوية. & $\begin{array}{l}\text { Nanostructured } \\
\text { magnetic foam }\end{array}$ \\
\hline كفاءة استهافلاك على البيئة الطبيعية. & معالجة و إصلاح البيئة الطبيعية. & 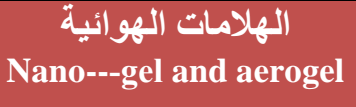 \\
\hline 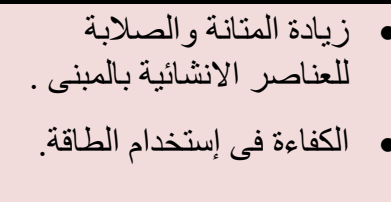 &  & $\begin{array}{l}\text { جسيمات النانو(اكسيد) } \\
\text { (الثتانيوم) } \\
\text { Titanium oxides } \\
\text { nanoparticles }\end{array}$ \\
\hline 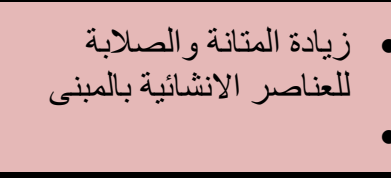 & 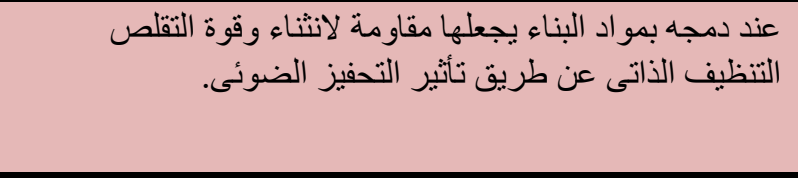 & $\begin{array}{l}\text { الايان نانق سبر (مئك } \\
\text { Fiber of } \\
\text { nanostructured } \\
\text { ceramic }\end{array}$ \\
\hline
\end{tabular}

2-8 الطاقة و آليات إستا(متها و إستخدام الطاقة الخضراء و والمتجددة: دور تقنية النانو الخضراء آلخاء بإنتاج الطاقة: (22)

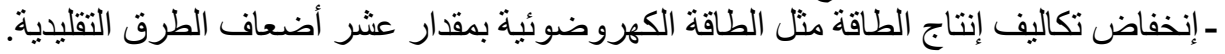

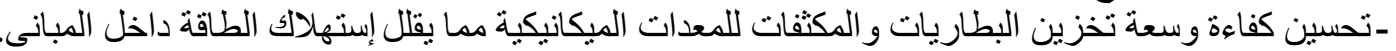


معالجة بتقنية النانو الخضر الطواء.

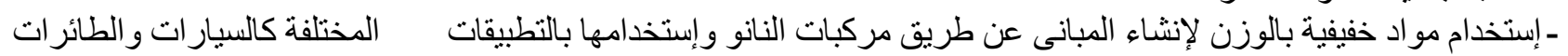

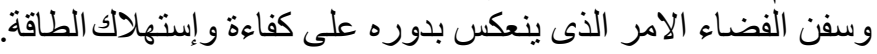

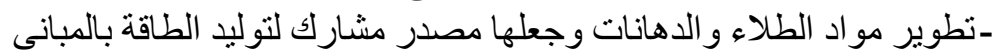

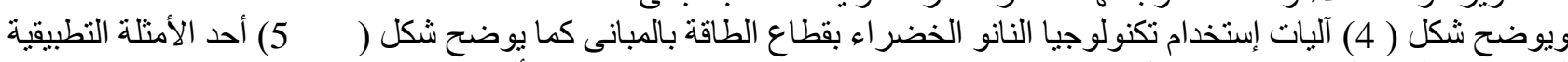

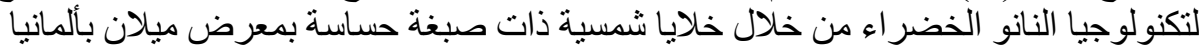




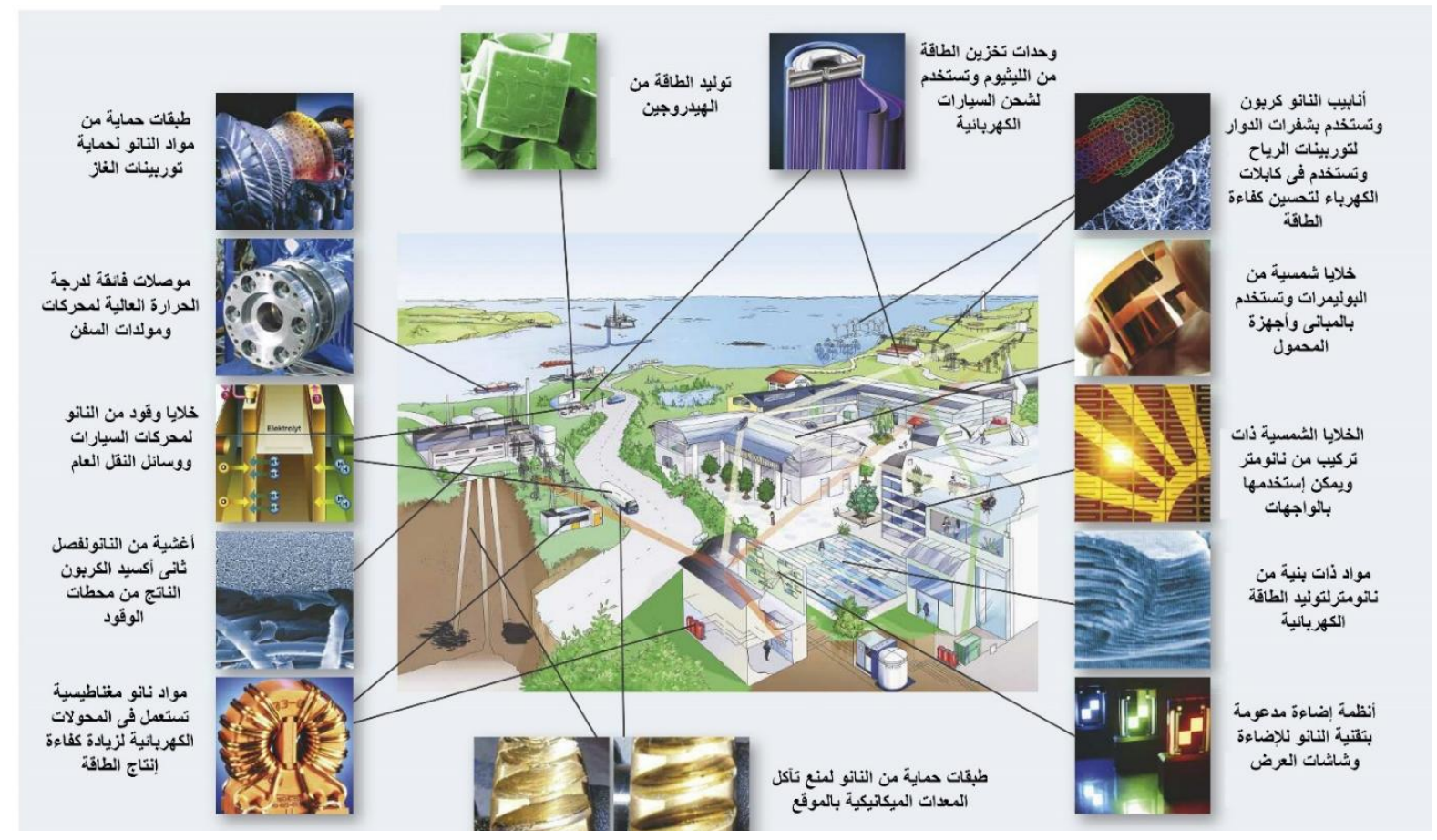

شكل (4) تكنولوجيا النانوالخضراء وإمثلة لتطبيقاتها الحالية والمستقبلية بقطاع الطاقة للمبانى المرجع : (22) بتصرف الباحث

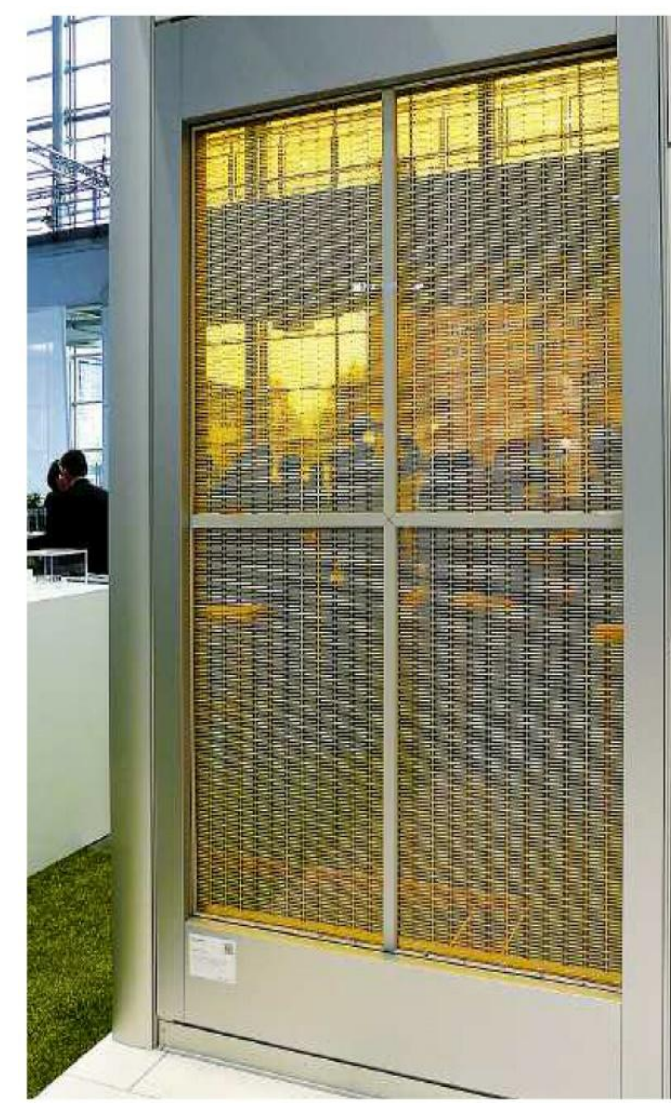



شكل (5) مثال لتطبيق تكنولوجيا النانو خضراء بالطاقة يمين

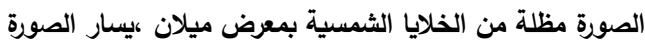
أكبر خلية شمسية ذات الصبغة الحساسة بالمانيا المرجع : (22) 
3-8 كفاعة إستهلاك المياه:

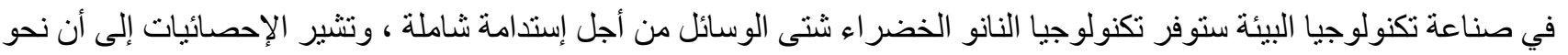



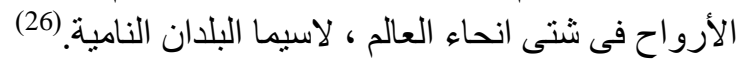
وتقدم تقنية النانو الخضر أنضاء العديد من الحلول لكفاءة وجودة المياه (مياه الثرب ـ مياه الصرف الصحى) كالاتى :

الميكانيكية و البصرية

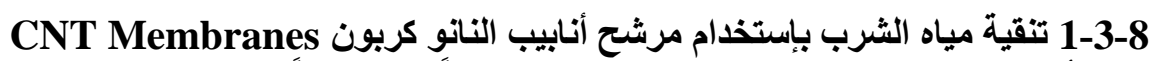




صفائح الجر افيت وشكلها كسياج من شعيرات دقيقة ، و أنابيب النانو الكربون المستخدمة للتنقية هي أنابيب


أغشية CNT لها إنجاز ات ملحوظة من حيث نفاذية المياه ، قدرة التحلية ، وتوفير التير في الطاقة المستخدمة لتنقية وتحلية المياه ويمكن أن تكون بمثابة ثروة الجيل القادم من حيث القدرة على تنقية المياه العالمية.كما أن استخدام أغثية



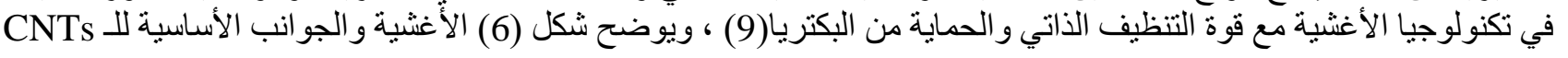

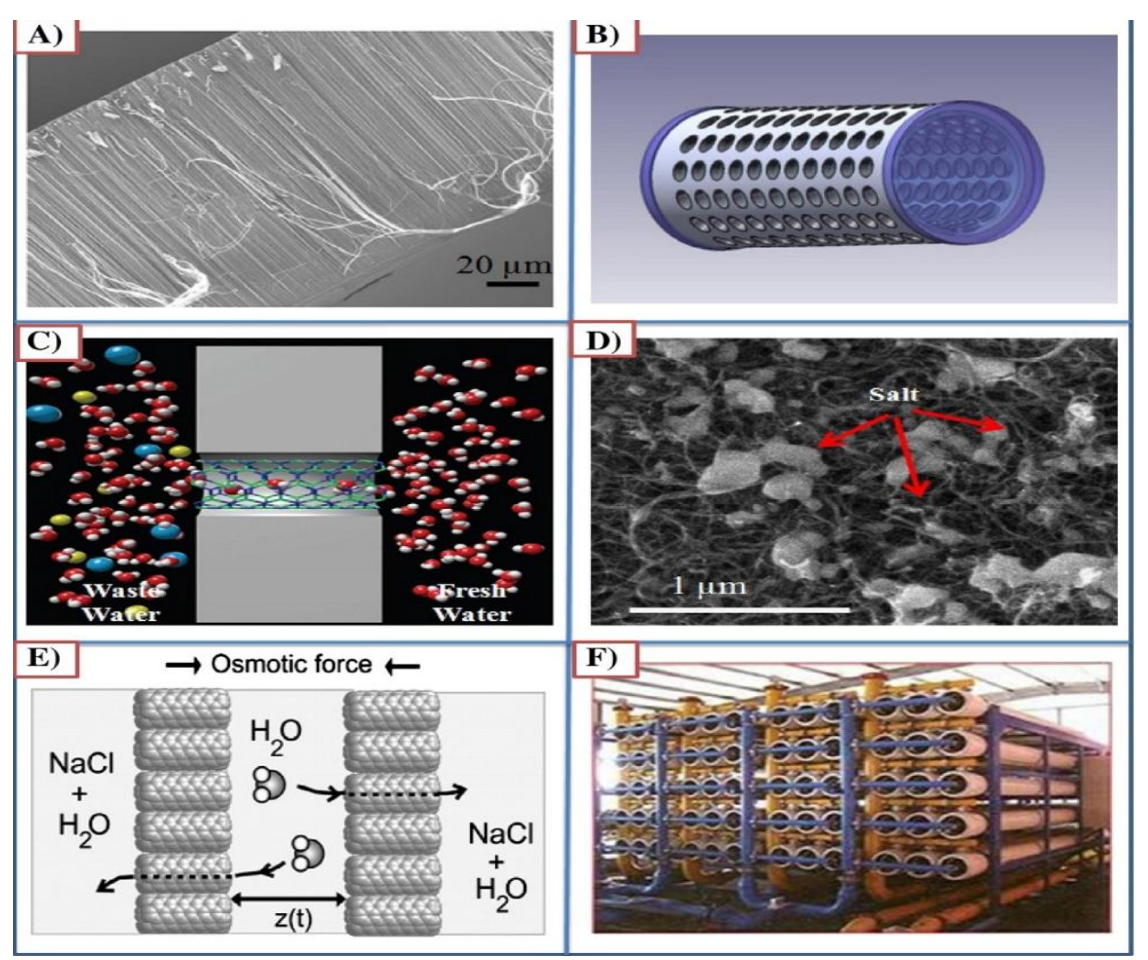

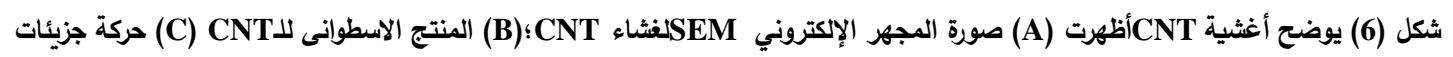

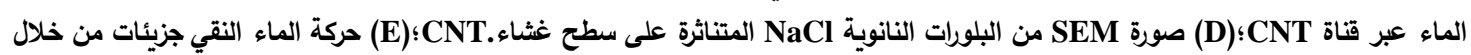



\section{2-3-8}



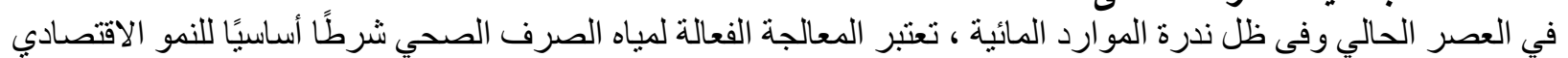

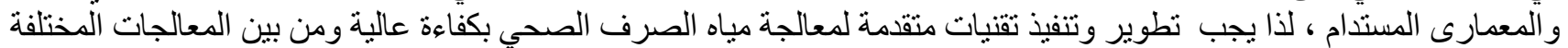

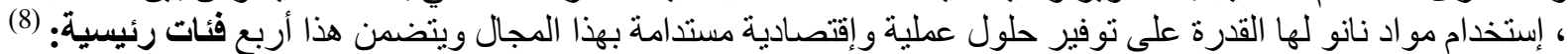

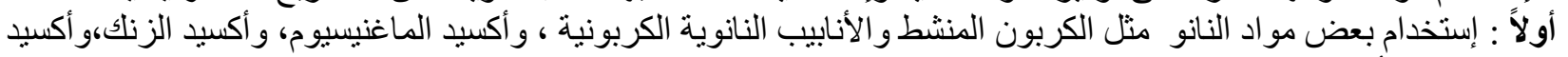

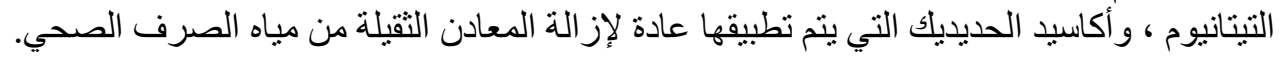




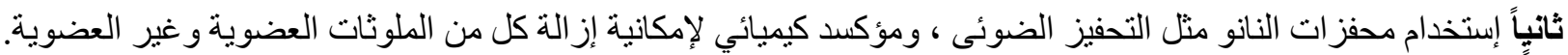

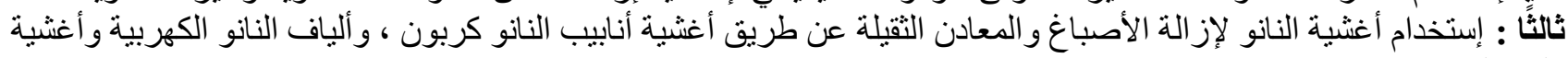
النانو الهجينة. رابعاً: تكامل تكنولوجيذة الهيا النانو مع العمليات البيولوجية مثل وجود مفاعل حيوي للأغشية وخلية الوقود الميكروبية للوصول إلى أحدث

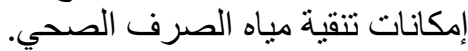
وقد طور فريق من العمل تابع لمركز تكنولوجياه لمنيا النانو للعلوم البيئية والبيولوجية التابع لجامعة رايس الأمريكية مرشحات الأغشية ،

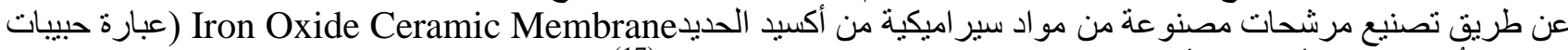

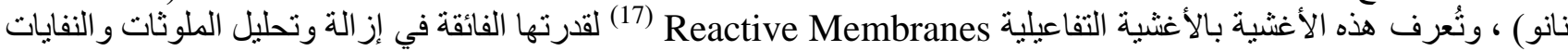
العضوية من الماءو وتطهير ها من أجل كفاءة وإعادة تدوير المياه بطريقة مستدامة عن طريق تكنولوجيا النانو الخضر اءهي من أجل بيئة

أفضل.

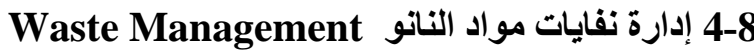

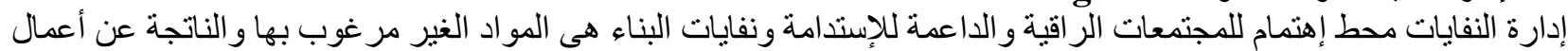

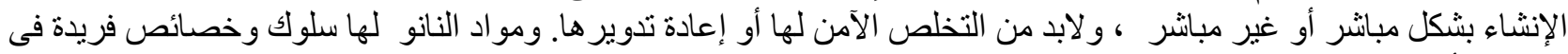

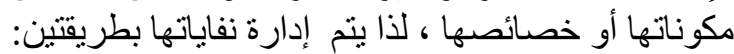



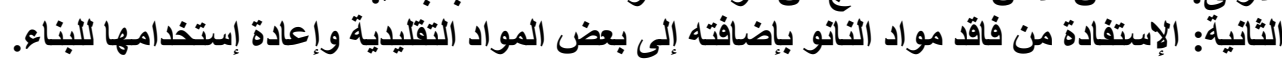

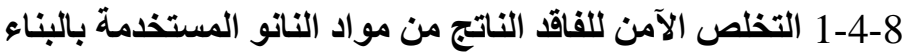



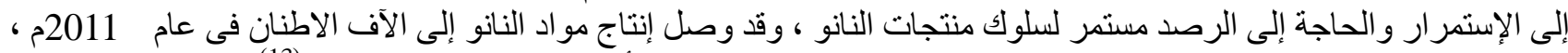





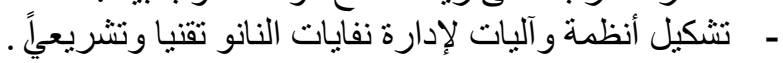

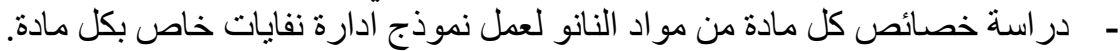

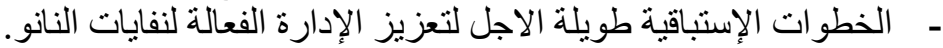

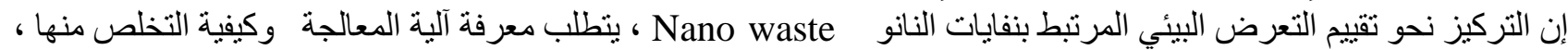



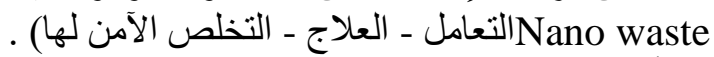
من أجل معالجة هذه التفاعلات المعقدة بشكل منهجي يجل الأن أن يكون هناك إطار للتخلص من نفايات مواد النانو ، كما هو مبين بشكل (7)

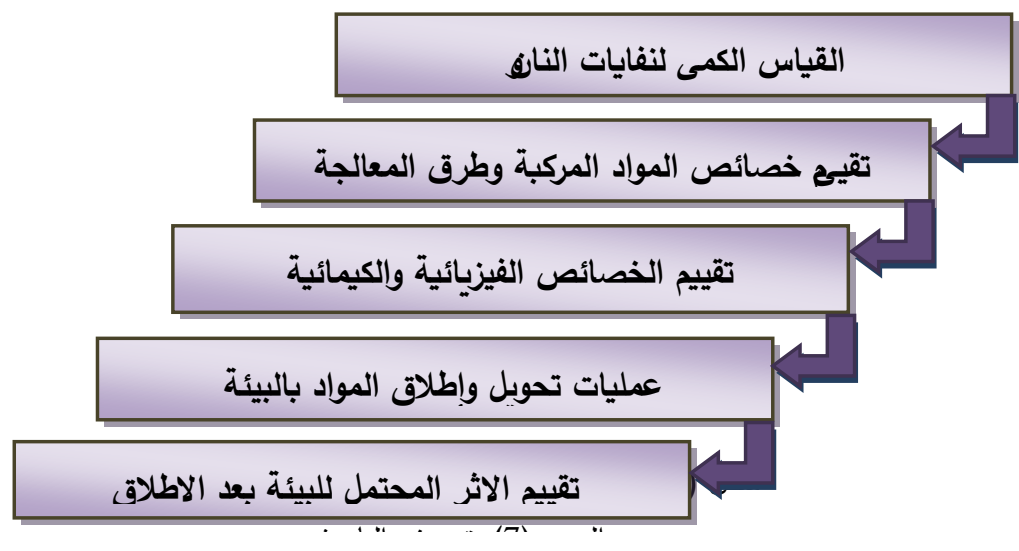

2-4-8 الإستفادة من فاقد مواد النانو بإضافته إلى بعض المواد التقليدية وإعادة إستخدمها للبناء.

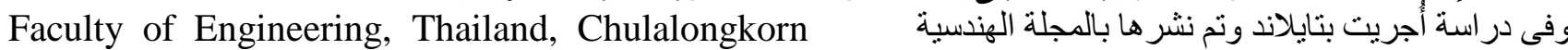
إعادة University

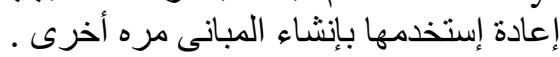

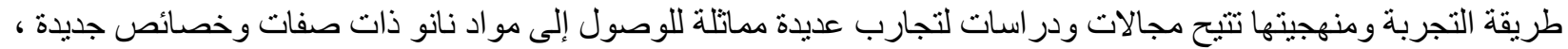

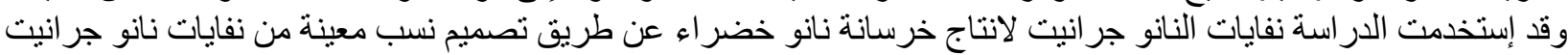

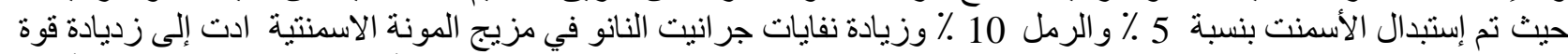
الضغط للمونة الاسمنتية الناتجة بنسبة 41 \% (عززت هذه النتيجة مجهر المسح 
كثافة و الحد الأدنى من الثقوق الدقيقة و عدد المسام ، وقد أجريت در اسة مقارنة بين المونة الاسمنتية الأخضر و المونة التقليدية ،

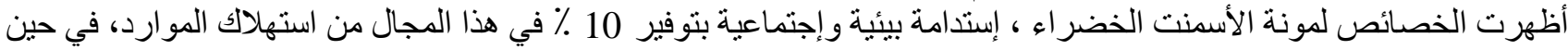

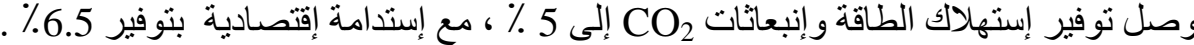

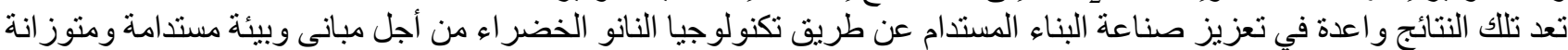

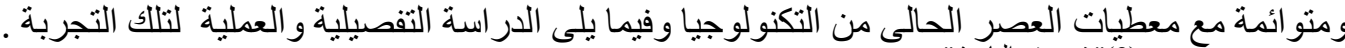

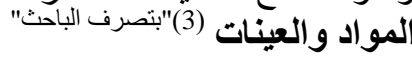

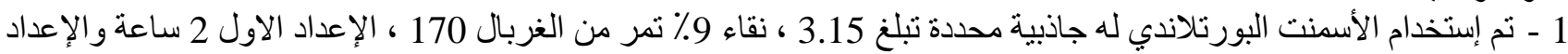
النهائي 3 ساعات و 12 د الاعنية.

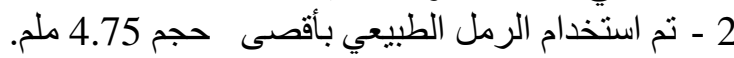

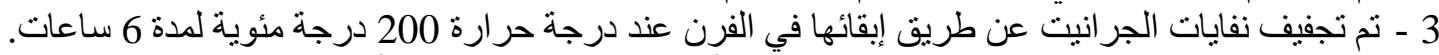

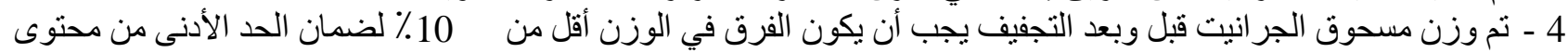

5 - نم الحفاظ على درجة الحر ارة بين 20-30 درجة مئوية،كانت تستخدم لإنتاج الخلطات الخرسانية

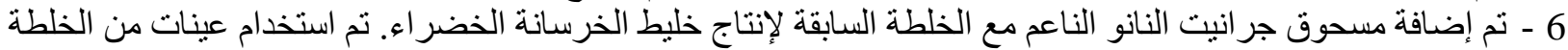
السابقة فى قو الب 50 × 50 × 50 ملم. وحفظ لمدة 24 ساعة ، ثم معالجة العينات في أحو اض المعالجة لخدة لمدة 28 يومًا. تصميم الخلطات تم إعداد مزيج من تصميم الخلطات لمونة الأسمنت عن طريق استبدال الأسمنت أو الرمل جزئيا أو كلاهما مع نسب مختلفة من حيث

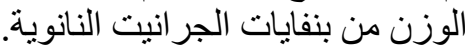

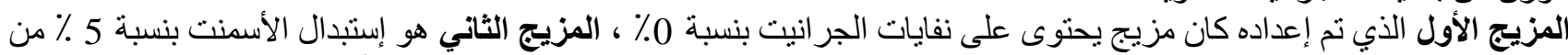

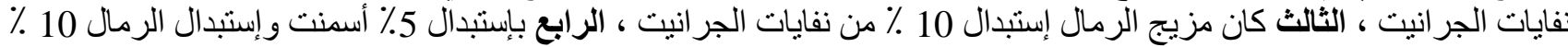

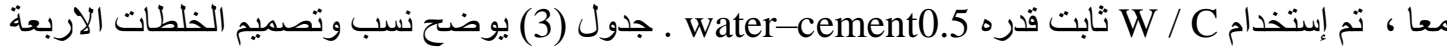

\begin{tabular}{|c|c|c|c|c|c|c|c|c|}
\hline \multicolumn{3}{|c|}{ Design Mix } & \multicolumn{4}{|c|}{ Components Quantity (gm) } & \multirow{2}{*}{$\begin{array}{l}\text { W/C } \\
\text { Ratio }\end{array}$} & \multirow{2}{*}{$\begin{array}{c}\text { Slump } \\
\text { Test } \\
\text { Results } \\
\text { (Cm) }\end{array}$} \\
\hline No & Name & Description & Cement & $\begin{array}{l}\text { Fine } \\
\text { Agg. }\end{array}$ & $\begin{array}{c}\text { Granite } \\
\text { waste }\end{array}$ & Water & & \\
\hline 1 & $\mathrm{CM}$ & نفايات نانو جرانيت 00 & 281.3 & 843.8 & 0.0 & 140.6 & 0.5 & 7.8 \\
\hline 2 & NC5 & |نفايات نانو جرانيت 5\% باستبدال الاسمنت & 267.2 & 843.8 & 14.1 & 133.6 & 0.5 & 6.9 \\
\hline 3 & NF10 & | نفايات نانو جرانيت 10\% باستبدال الرمال & 281.3 & 759.4 & 84.4 & 140.6 & 0.5 & 5.7 \\
\hline 4 & NC5+NF10 & | استبدال5\%أسمنت 10\%زمل بالجرانيت نانو & 267.2 & 759.4 & 98.4 & 133.6 & 0.5 & 5.4 \\
\hline
\end{tabular}

جدول(3) نسب وتصميم الاربعة خلطات لانتاج خرسانة النانوالخضراء

- إختبار قوة الضغط

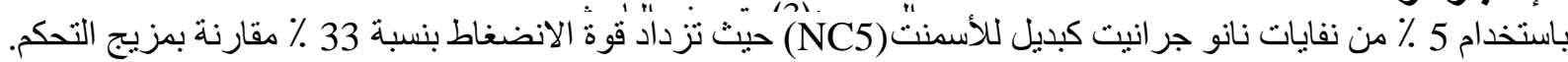

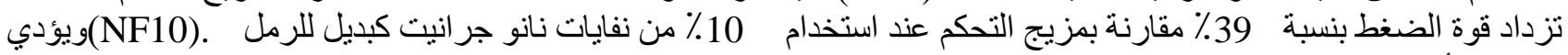

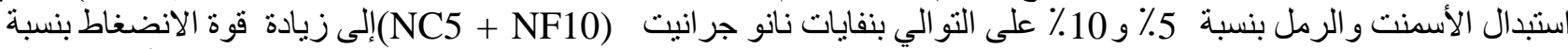

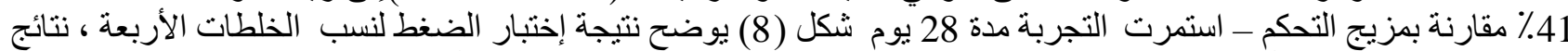

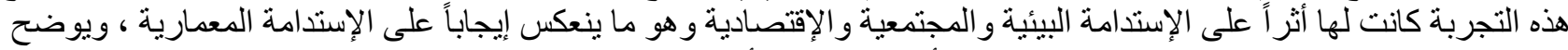
جدول (4) مقارنة بين مونة الإسمنت التقليدى ومونة أسمنت النانو الأخضر الأنس
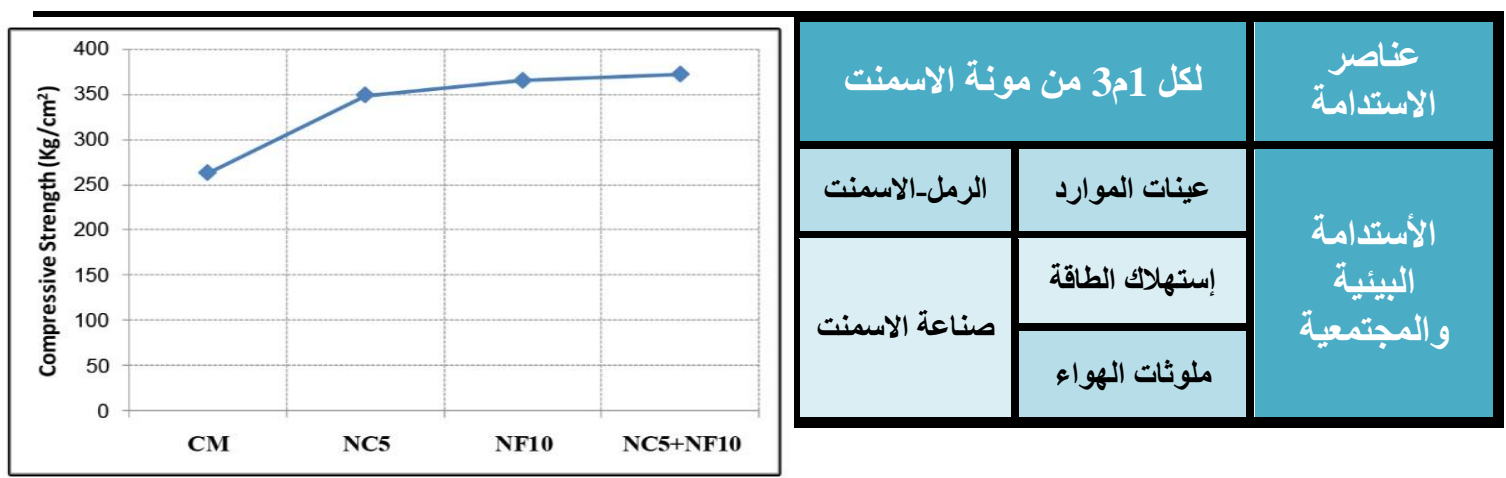

شكل (8) اختبار الضغط لنسب اتبدال نفايات الجرانيت بالرمل والاسمنت 


\begin{tabular}{|c|c|c|c|c|c|}
\hline & إستخدام 193كجم من نفيات الجرانيت & لا يوجد & \multirow{2}{*}{ نفايات الجرانيت } & فاقد المواد & \\
\hline & 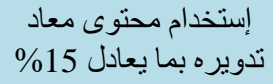 & لا يوجد & & إعادة التدوير & \\
\hline \multirow[t]{2}{*}{$\begin{array}{l}\text { توفير } \\
\text { \%6.5 }\end{array}$} & 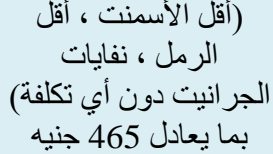 & 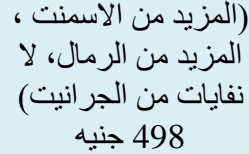 & بحسب تصميم & التكلفة & \multirow{2}{*}{ 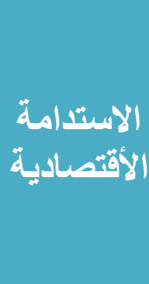 } \\
\hline & 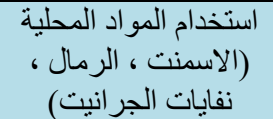 & استخدام المو اد المحلية & مواد & الانتاج المحلى & \\
\hline
\end{tabular}

جدول (4) مقارنة بين مونة الاسمنت التقليدى والأخضر بإستخام نفايات نانو الجرانيت المرجع : الباحث إعتماداً على مرجع (3)

التجر

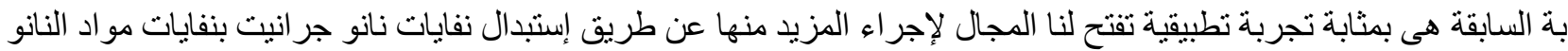

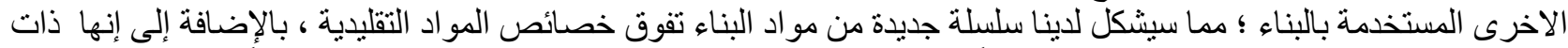

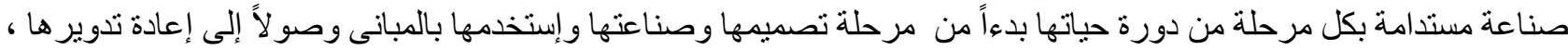

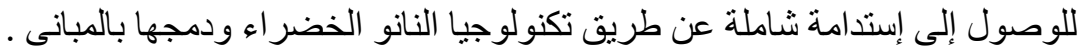

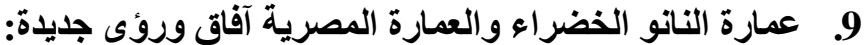

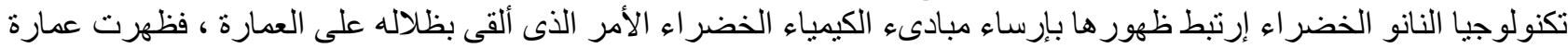

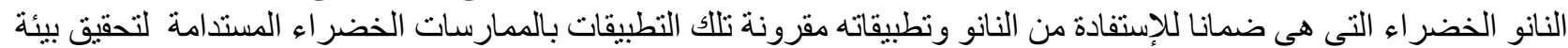

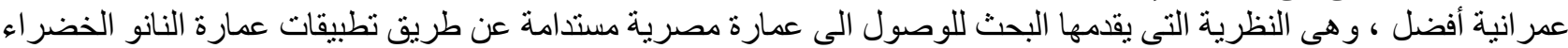

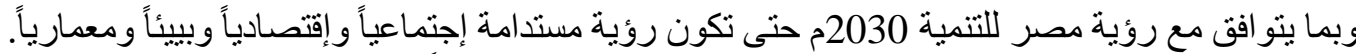

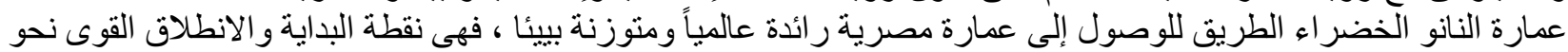

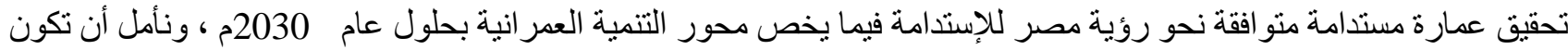

العمارة المصرية فى صدارة هذا المضمار ، وفيما يلى بعض النقاط العملية للإستفادة من تطبيقات عمارة النانو الخضر اءء بالعمارة

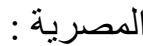

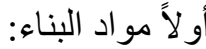

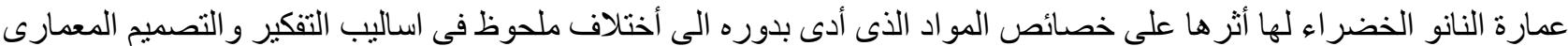

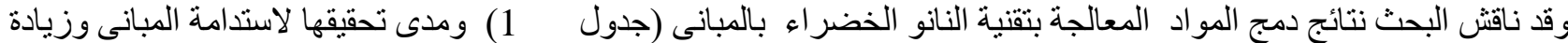

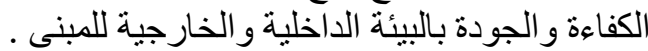

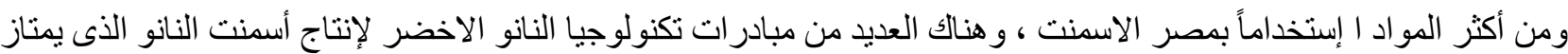

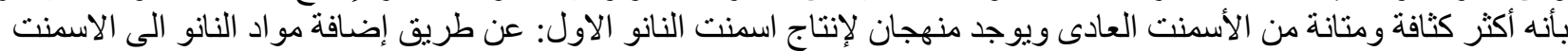

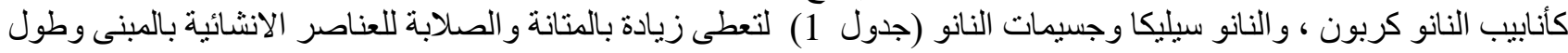

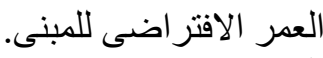

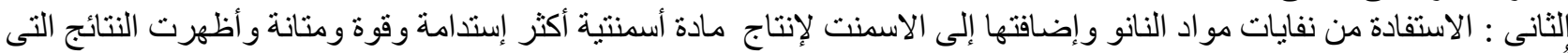

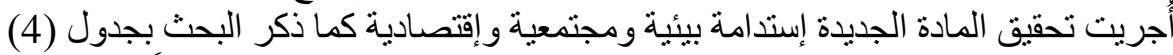

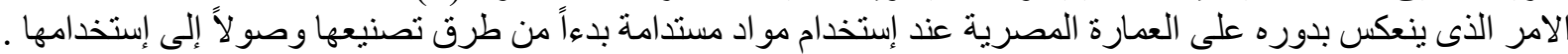
تُانياً قطاع الطاقة: تطبيقات عمارة النانو الخضر اء بالطاقة لها أثراً إيجابياً بكفاءة ونوليد و إستهلاك الطاقة ، حيث يمكن أُستخدمها بالخلايا الثمسية 
ومو اد الدهانات وجعلها مصدر مشارك لتوليد الطاقة بالمبنى ، كما ذكر البحث بشكل (4).

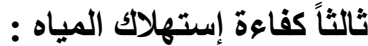

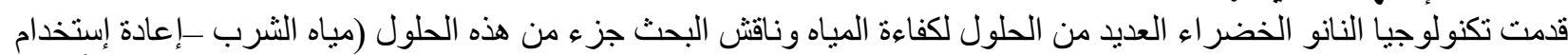

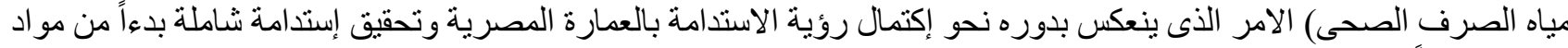

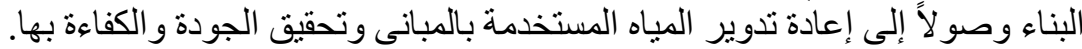

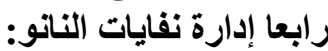

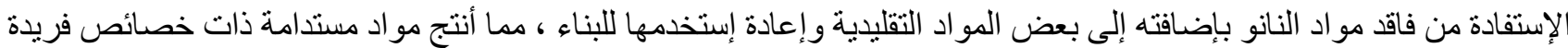

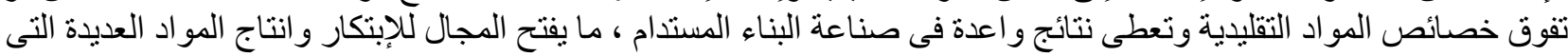

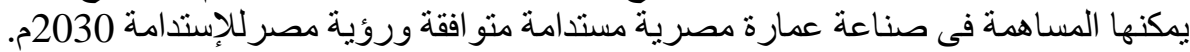

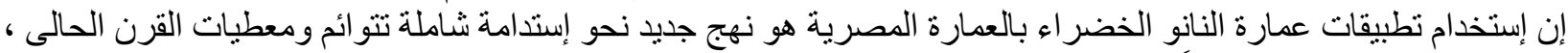

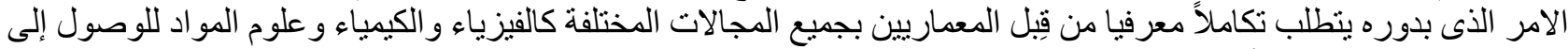
رؤى عملية و علمية من شأنها تحقيق و آفاق جديدة نحو إستدامة العمارة المصرية.

1. تطبيقات النانو بالعمارة أتاحت عالما جديدا من مو اد البناء المتقدمة والأكثر كفاءة على نطوير نفسها وفقا لمعطبات التصميم

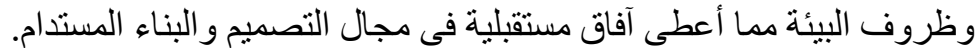

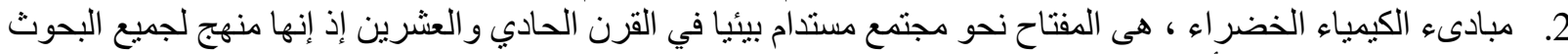

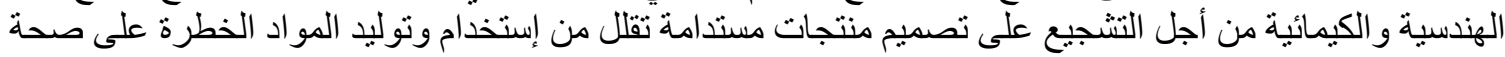
الإنسان و البيئية.

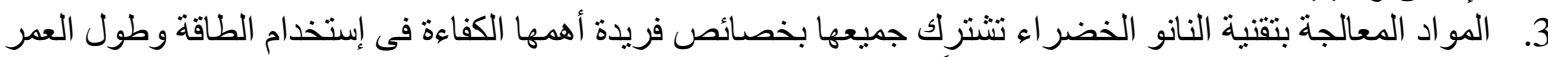

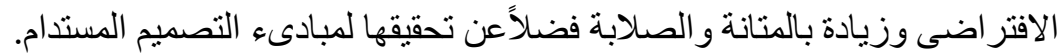
4. تكنولوجيا النانو الخضر اء أحدثت طفرة كبيرة بمجال الطاقة كالخلايا الثمسية و غير ها من التطبيقات الخاصة بالطاقات المتجددة.

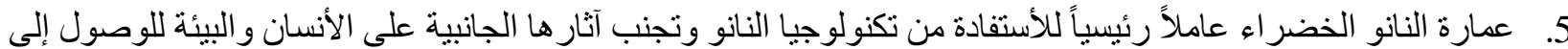

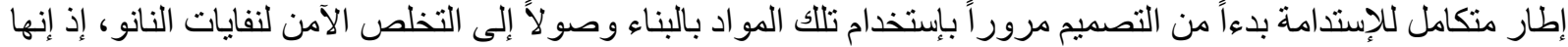

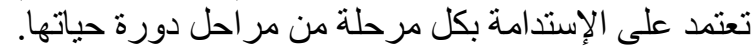

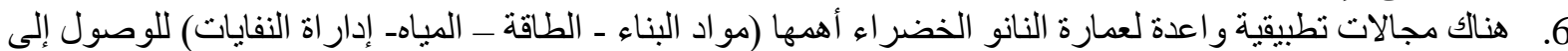
إستدامة معمارية متكاملة.

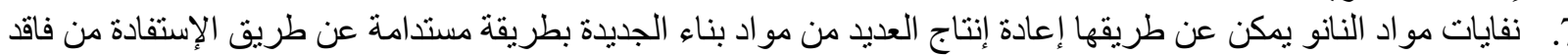

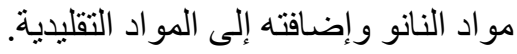
8. تكامل المعرفة المعمارية مع المجالات الفي الفيزئيائية و الكيمائية و علم المو اد سيفتح أمامنا رؤى عملية و علمية جديدة من شأنها تحقيق إستدامة شاملة. 11. 11 التوصياث

1. يوصى البحث بالعمل على إستبدال مو اد البناء القائمة بأخرى تعنمد على تكنولوجيا النانو الخضر اءو عن طريق الاستعانة

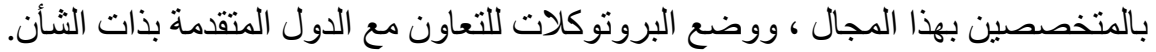

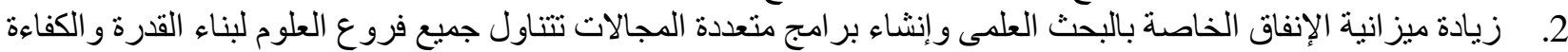

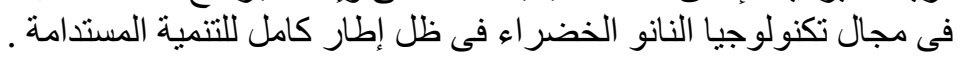

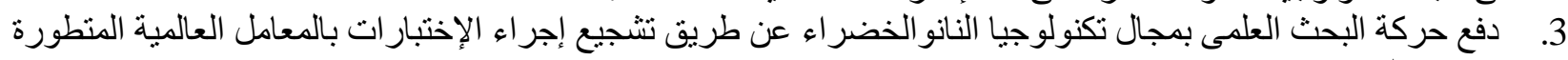

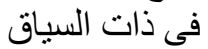

4. إجر اء أبحاث مشتركة مع باحثين عالميين والإستفادة بتطابيقاتها بالعمارة المصرية وتشجيع القطاع الخاص بإستخدام تلك الكي

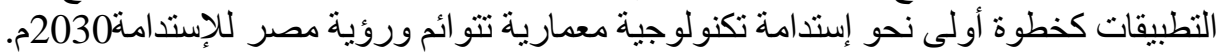




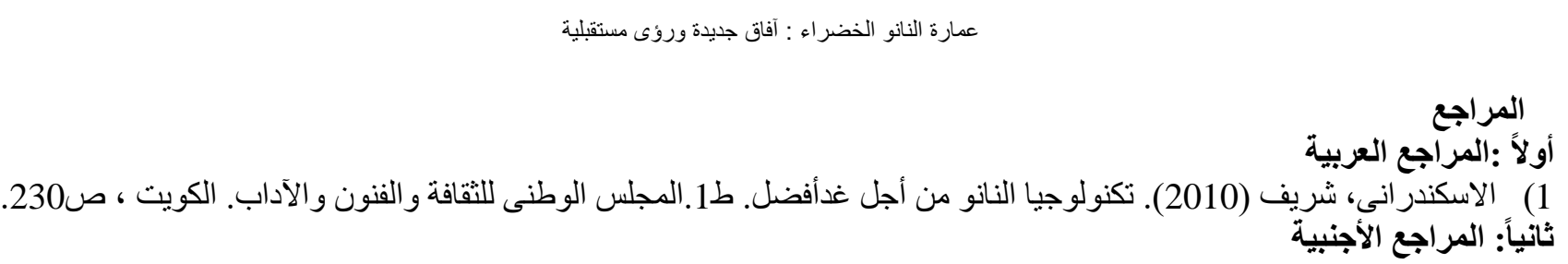

2) Rizzuto, C., Pugliese, G., Bahattab, M. A., Aljlil, S. A., Drioli, E., \& Tocci, E. (2018). "Multiwalled carbon nanotube membranes for water purification". Separation and Purification Technology, 193, 378-385.

3) Bakhoum, E. S., Garas, G. L. K., Allam, M. E., \& Ezz, H. (2017).” The Role of Nano-Technology in Sustainable Construction: A Case Study of Using Nano Granite Waste Particles in Cement Mortar”. Engineering Journal, 21(4), 217-227.

4) Hernández-Moreno, S., \& de la Torre, S. S. (2017). "Nano-technological products in architecture and construction". HOLOS, 2, 35-51.

5) Anjum, M., Miandad, R., Waqas, M., Gehany, F., \& Barakat, M. A. (2016)." Remediation of wastewater using various nano-materials". Arabian Journal of Chemistry.

6) Paper, C. (2015). "Green Nano-materials with Examples of Applications Green Nano-materials with Examples of Applications", (April), 0-9.

7) Boldrin, A., Hansen, S. F., Baun, A., Hartmann, N. I. B., \& Astrup, T. F. (2014). "Environmental exposure assessment framework for nanoparticles in solid waste". Journal of Nanoparticle Research, 16(6), 2394.

8) Das, R., Ali, M. E., Hamid, S. B. A., Ramakrishna, S., \& Chowdhury, Z. Z. (2014). "Carbon nanotube membranes for water purification: a bright future in water desalination. Desalination", 336, 97-109.

9) Ba Banerjee, S., \& Akuli, R. K. (2014). "Advantages of green technology". Social Issue and Environment Problems, 3(9), 97-100.

10) Science, N., \& Technology, N. (2013). "Nano Science and Nano Technology", 5(11), 478-488.

11) Schulte, P. A., McKernan, L. T., Heidel, D. S., Okun, A. H., Dotson, G. S., Lentz, T. J., ... Branche, C. M. (2013). "Occupational safety and health, green chemistry, and sustainability: a review of areas of convergence". Environmental Health, 12(1), 31.

12) Smith, G. B. (2011,september)." Green nanotechnology". In, Nanostructured Thin Films IV, (Vol 8104,p 810402).International Society for optics and photonics.

13) Musee, N. (2011)." Nanowastes and the environment: Potential new waste management paradigm". Environment International, 37(1), 112-128

14) Hemeida, F.A.E.A.O.(2010). "Green nanoarchitecture”.M.Thesis, Unversity of Alexsandria,Arch.Dpt. p79.

15) Roco, M. C., Mirkin, C. A., \& Hersam, M. C. (2010). "Nanotechnology research directions for societal needs in 2020 " :summary of international study

16) Sattari, A. (2009). Nanotechnology and Sustainability:A Critical Review of Current Trends and Future Development. KTH School of Industrial Engineering and Management Amir, Stockholm

17) woodrow wilson international center. (2009). "Green Nano Technology its Easier than you think".

18) Eckelman, M. J., Zimmerman, J. B., \& Anastas, P. T. (2008). "Toward green nano: E-factor analysis of several nanomaterial syntheses". Journal of Industrial Ecology, 12(3), 316-328.

19) Morris,J.,\&Willis,J.(2007). “US Environmental Protection Agency Nanotechnology white paper”. US Environmental Protection Agency,Washington,Dc. P. 136.

20) (2017). "Global Nanotechnology Market To Reach $\$ 48.9$ Billion In 2017."

ثالثاً : مواقع شبكة المعلومات الدولية https://www.bccresearch.com/pressroom/nan/global-nanotechnology-market-reach-\$48.9-billion2017.

21) https://nanoscience.conferenceseries.com/2017/

22) W. Luther, "Application of Nano- technologies in the Energy Sector," https://Www.HessenNanotech.

23) Green nanotechnology." https://Www.en.wikipedia.org/wiki/Green nanotechnology\#cite note-4.

24) "Environment and Green Nano - Nanotechnology Project." http://www.nanotechproject.org/topics/green/.

25) What is Green Nanotechnology?" http://www.azocleantech.com/article.aspx?ArticleID=330

26) "Water pollution." http://www/en.wikipedia.org/wiki/Water_pollution 